\title{
Hispanic Youth Visits to Food and Beverage Company Websites
}

\author{
Maia Hyary ${ }^{1, *}$ and Jennifer L. Harris ${ }^{2}$
}

\begin{abstract}
Purpose: To measure disparities in exposure to food/beverage websites by Hispanic youth. Methods: Observational study using market research panel data compared frequency and time spent visiting food/beverage websites and the Internet overall for Hispanic and non-Hispanic children (6-11 years) and youth (6-17 years).

Results: Hispanic children and youth, particularly Spanish-speaking youth, were less likely to visit the Internet overall, but more likely to visit food/beverages websites, compared with their non-Hispanic peers.

Conclusions: Food and beverage company websites disproportionately appeal to Hispanic youth. Public health advocates and companies should take action to reduce Hispanic youth exposure to unhealthy food marketing online.
\end{abstract}

Keywords: Hispanic; Internet; marketing; obesity

\section{Introduction}

Public health experts raise concerns that disproportionate exposure to unhealthy food marketing contributes to poor diet and disparities in obesity and related diseases among Hispanic youth. ${ }^{1-12}$ Furthermore, food and beverage companies often target marketing for nutrient-poor products such as candy, sugary drinks, snack foods, and fast-food restaurants to Hispanic audiences, including youth. ${ }^{13-15}$

Previous research has documented disproportionate exposure to unhealthy food marketing by Hispanic youth in their communities and on TV. ${ }^{16,17}$ However, marketing to Hispanic youth on the Internet also may pose health risks. Food and beverage companies have increased their marketing aimed at all youth on digital media, ${ }^{18}$ including food company websites. ${ }^{19}$ Previous research has documented frequent youth visitors to food company websites, including those featuring child-directed games. ${ }^{13,20,21}$ However, research has not assessed Hispanic youth's exposure to food and beverage marketing on the Internet. This research utilizes syndicated market research data to compare Internet behavior, including visits to food/beverage websites, for Hispanic and non-Hispanic youth.

\section{Methods}

Data

Researchers obtained data for Hispanic and nonHispanic youth Internet visitors (6-17 years) for July 2012 through June 2013, using comScore's Media Metrix Key Measures Report. Data for Hispanic and nonHispanic child visitors (6-11 years) and for Hispanic youth visitors segmented by household language preference (primarily English speaking, bilingual, and primarily Spanish speaking) also were obtained for total Internet and higher volume websites. Household language preferences are self-identified by the head-of-household.

comScore conducts monthly phone surveys, weighted to be representative of the U.S. population, to estimate Internet users by age and ethnicity. ${ }^{22}$ It also tracks

${ }^{1}$ Heller School for Social Policy and Management, Brandeis University, Waltham, Massachusetts.

${ }^{2}$ Rudd Center for Food Policy and Obesity, University of Connecticut, Hartford, Connecticut. 
visitors to the total Internet and individual websites through its panel of approximately 350,000 active monthly Internet users in the United States, the largest U.S. panel, including individual users within a household. comScore provides data for websites visited on personal computers by at least 30 panel members in a given quarter, but does not provide visits on mobile devices for youth under age 18 .

\section{Measures}

Measures are reported by age group, ethnicity, and language preference for the total Internet and for individual websites with available data. ${ }^{22}$ comScore provided four quarterly reports of average monthly data, which researchers averaged to obtain mean monthly numbers for the 12-month period examined. Visits-per-visitor, minutes-per-visit, and minutes-per-visitor provided frequency and duration of visits. Researchers used these measures to calculate (1) audience reach for individual food/beverage websites (unique visitors-per-month for the website/the total Internet) per demographic group; (2) Hispanic audience ratios for individual websites (Hispanic audience reach/non-Hispanic audience reach); (3) Hispanic audience ratios for minutes-per-visitor (average monthly minutes for Hispanic visitors/non-Hispanic visitors); and (4) Spanish-speaking audience ratios (audience reach for primarily Spanish-speaking and bilingual Hispanic youth/primarily English-speaking Hispanic youth). Hispanic audience ratios $>1.0$ indicate that visits and/or time spent on the website were higher for Hispanic individuals than for non-Hispanic individuals. Spanish-speaking ratios $>1.0$ indicate that visits and/or time spent on the website were higher for individuals living in Spanish-speaking households than those in primarily English-speaking households.

To identify popular food/beverage websites, researchers used comScore's Media Metrix Key Measures Report to select all websites from 48 food and beverage companies engaged in youth-directed marketing. ${ }^{18}$ Researchers then excluded non-U.S. URLs and websites promoting other types of products (e.g., household cleaners and baby foods), websites aimed at company shareholders or employees, and those with fewer than 1000 unique Hispanic youth visitors-per-month and/or with less than three quarters of available data.

Using content analysis, researchers classified food/ beverage websites according to product category and child-directed content. The codebook for child-directed content was adapted from a previous study that identified messages appealing to children, ${ }^{13}$ including techniques such as advergames, anthropomorphized food, and animated characters. Two independent coders achieved 97\% agreement for product category and $82 \%$ agreement for child-directed messages. Researchers reconvened to reach a consensus on discrepancies.

\section{Statistical analysis}

One-sample $t$-tests assessed whether Hispanic and Spanish-speaking audience ratios differed significantly from 1.0 (i.e., equal audience reach for Hispanic and non-Hispanic individuals, or youth living in Spanishspeaking versus primarily English-speaking households). Statistical analyses were conducted in 2015 using STATA, version 14.0.

\section{Results}

Internet overall

On average, $36 \%$ of Hispanic youth (6-17 years) visited the Internet on a given day, averaging $\sim 24$ minutes-pervisit (Table 1). However, Hispanic youth visited somewhat less often than non-Hispanic youth. Primarily English speakers comprised $48 \%$ of the Hispanic youth Internet audience, and bilingual and primarily Spanish speakers comprised approximately one-quarter each.

Table 1. Total Internet Visits by Hispanic and Non-Hispanic Youth and Children

\begin{tabular}{|c|c|c|c|c|c|}
\hline & $\begin{array}{l}\text { Mean monthly } \\
\text { unique visitors to } \\
\text { the Internet }(000)\end{array}$ & $\begin{array}{l}\text { Mean } \\
\text { monthly visits- } \\
\text { per-visitor }\end{array}$ & $\begin{array}{l}\text { Mean } \\
\text { minutes- } \\
\text { per-visit }\end{array}$ & $\begin{array}{l}\text { Mean monthly } \\
\text { minutes- } \\
\text { per-visitor }\end{array}$ & $\begin{array}{c}\text { Mean daily } \\
\text { audience } \\
\text { penetration, \% }\end{array}$ \\
\hline Hispanic youth (6-17 years) & 6495.3 & 28.8 & 23.8 & 688.7 & 35.8 \\
\hline Primarily English speaking ${ }^{a}$ & 3138.4 & 30.7 & 24.3 & 749.5 & 36.8 \\
\hline Bilingual & 1726.1 & 28.0 & 23.4 & 657.8 & 36.4 \\
\hline Primarily Spanish speaking & 1630.9 & 25.9 & 23.1 & 601.7 & 33.4 \\
\hline Non-Hispanic youth (6-17 years) & 36207.8 & 34.8 & 24.1 & 839.8 & 40.2 \\
\hline Hispanic children (6-11 years) & 3274.3 & 10.5 & 18.9 & 199.2 & 19.0 \\
\hline Non-Hispanic children (6-11 years) & 18161.3 & 13.5 & 19.1 & 259.1 & 21.4 \\
\hline
\end{tabular}

Source: comScore Media Metrix Key Measures report, July 2012-June 2013.

aHousehold language preference. 
Time spent on the Internet increased with amount of English spoken in the household. On average, Hispanic youth in households that primarily spoke English spent 2.5 more hours-per-month online than primarily Spanish speakers. However, primarily English-speaking Hispanic youth spent $\sim 1.5$ fewer hours-per-month online than non-Hispanic youth. Just $19 \%$ of Hispanic children (6-11 years) visited the Internet on a given day, and they spent approximately 1 less hour-per-month than nonHispanic children.

\section{Food/beverage websites}

comScore identified 274 U.S-based food/beverage company websites, of which $24 \%(n=67)$ averaged 1000 or more unique Hispanic youth visitors-per-month and met the other inclusion criteria. Approximately onethird $(n=20)$ also attracted enough Hispanic child (611 years) visitors to measure, and one-third $(n=21)$ had data for Hispanic youth by language preference.

Despite fewer visits to the total Internet, Hispanic youth were significantly more likely to visit food/beverage websites than non-Hispanic youth $\left(M_{\text {Hispanic youth audience ratio }}=1.72,95 \% \mathrm{CI}=1.11-2.33\right.$, $p=0.02)$. These sites were also relatively more popular with Spanish-speaking youth $\left(M_{\text {Spanish-speaking youth audi- }}\right.$ ence ratio $=1.35,95 \% \mathrm{CI}=1.00-1.70, p=0.04)$ and with Hispanic children $\left(M_{\text {Hispanic }}\right.$ child audience ratio $=1.67$, $95 \% \mathrm{CI}=1.00-2.34, p=0.05)$ than with non-Hispanic children.

Restaurants and multiproduct sites represented almost one-half of the food/beverage sites examined (Table 2). Compared with non-Hispanic youth, His- panic youth were more likely to visit 31 of the identified sites (46\%), including the 14 sites featuring childdirected messages. Furthermore, Spanish-speaking youth were equally or more likely to visit most of the food/beverage websites with language preference data than primarily English-speaking Hispanic youth, including all sites with child-directed messages.

Table 3 presents the food/beverage websites visited most frequently $(n=31)$ by Hispanic youth and additional sites with data by language preference and for Hispanic children. Sites that were relatively more popular with Hispanic youth than with non-Hispanic youth included ChuckeCheese.com, HappyMeal.com, the Lunchables website, FrostedFlakes.com, and two Spanish language websites (ComidaKraft.com and McDonald's MeEncanta.com). Among Hispanic children (under 12 years), ChuckECheese.com, FrootLoops.com, HappyMeal.com, TacoBell.com, LuckyCharms.com, and SubwayKids.com were relatively more popular.

\section{Conclusion}

Hispanic children and youth, particularly youth in Spanish-speaking households, visited food/beverage websites at higher rates than their non-Hispanic counterparts, despite fewer visits to the Internet overall. The frequency with which youth in Spanish-speaking households visited popular food and beverage websites compared with primarily English-speaking Hispanic youth raises further concerns due to the potential for these sites to reinforce preferences for an "American" diet among less acculturated youth, which could contribute to Hispanic youth's worsening diet with greater

Table 2. Categories of Food and Beverage Websites Visited by Hispanic Children (6-11 years) and Youth (6-17 Years)

\begin{tabular}{|c|c|c|c|c|c|c|c|}
\hline \multirow[b]{3}{*}{ Product category } & \multirow{3}{*}{$\begin{array}{c}\text { No. of } \\
\text { websites }\end{array}$} & \multirow{3}{*}{$\begin{array}{l}\% \text { of } \\
\text { total }\end{array}$} & & & \multicolumn{3}{|c|}{ Audience share ratios (range) } \\
\hline & & & \multicolumn{2}{|c|}{$\begin{array}{l}\text { Unique Hispanic youth } \\
\text { visitors-per-month }(000)\end{array}$} & \multirow{2}{*}{$\begin{array}{c}\text { Hispanic } \\
\text { youth } \\
(6-17 \text { years })^{a} \\
(n=67)\end{array}$} & \multirow{2}{*}{$\begin{array}{c}\text { Hispanic } \\
\text { children } \\
{\text { (6-11 years })^{b}}^{\text {b }}(n=20)\end{array}$} & \multirow{2}{*}{$\begin{array}{c}\text { Spanish- } \\
\text { speaking youth } \\
(6-17 \text { years })^{c} \\
(n=21)\end{array}$} \\
\hline & & & Median & Range & & & \\
\hline Restaurants & 19 & 28 & 6.7 & $1.1-65.1$ & $0.4-6.6$ & $0.6-7.3$ & $0.5-3.3$ \\
\hline Multiproduct & 13 & 19 & 5.0 & $1.3-16.3$ & $0.3-17.8$ & $0.8-1.9$ & $0.7-0.9$ \\
\hline Beverages & 12 & 18 & 2.1 & $1.0-12.5$ & $0.4-3.0$ & 1.9 & $1.2-1.5$ \\
\hline Cereals & 7 & 10 & 3.6 & $2.6-25.3$ & $0.9-2.4$ & $0.8-1.1$ & $1.4-23.0$ \\
\hline Snacks & 7 & 10 & 1.6 & $1.0-2.5$ & $0.6-3.4$ & * & * \\
\hline Candy & 6 & 9 & 1.4 & $1.0-2.2$ & $0.7-1.0$ & 1.0 & * \\
\hline Other & 3 & 4 & 2.2 & $1.0-14.7$ & $1.6-2.9$ & 1.6 & 1.9 \\
\hline Total sites with child-directed messages & 14 & 21 & 4.2 & $1.2-65.1$ & $0.8-3.4$ & $1.4-2.1$ & $1.0-3.3$ \\
\hline Other popular sites & 53 & 79 & 2.7 & $1.0-49.7$ & $0.3-17.9$ & $0.6-7.3$ & $0.5-2.9$ \\
\hline
\end{tabular}

Source: comScore Media Metrix Key Measures report, July 2012-June 2013.

*Data were not available in comScore for these demographic groups.

${ }^{a}$ Hispanic youth (6-17 years) audience reach/non-Hispanic youth audience reach.

${ }^{b}$ Primarily Spanish-speaking and bilingual Hispanic youth audience reach/primarily English-speaking Hispanic youth audience reach.

'Hispanic child (6-11 years) audience reach/non-Hispanic youth audience reach. 


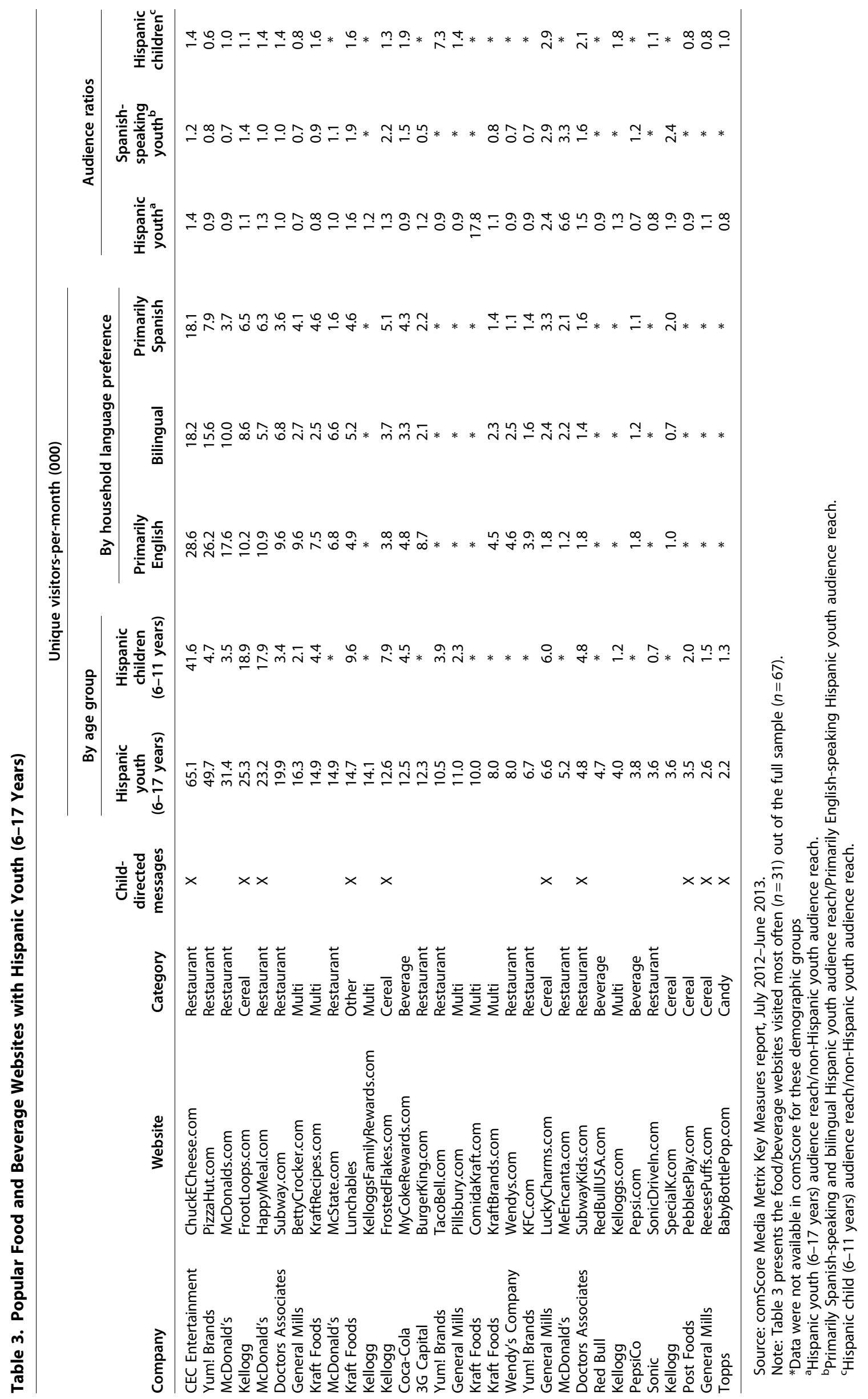


acculturation. ${ }^{23}$ Further research is needed to understand why Hispanic youth disproportionately visit food/beverage websites to help inform potential actions to reduce their exposure to unhealthy food marketing. However, given higher rates of obesity and diet-related diseases among Hispanic youth, ${ }^{1,4}$ food and beverage companies should not target marketing of unhealthy products to Hispanic youth online.

\section{Author Disclosure Statement}

No competing financial interests exist.

\section{References}

1. Ogden CL, Carroll MD, Lawman HG, et al. Trends in obesity prevalence among children and adolescents in the United States, 1998-1994 through 2013-2014. JAMA. 2016;315:2292-2299.

2. Basen-Engquist $K$, Chang M. Obesity and cancer risk: recent review and evidence. Curr Oncol Rep. 2011;13:71-76.

3. Franks PW, Hanson RL, Knowler WC, et al. Childhood obesity, other cardiovascular risk factors, and premature death. $\mathrm{N}$ Engl J Med. 2010;362:485-493.

4. Lau M, Lin H, Flores G. Racial/ethnic disparities in health and health care among U.S. adolescents. Health Serv Res. 2012; p. 2031-2059.

5. Narayan K, Boyle JP, Thompson TJ, et al. Lifetime risk for diabetes mellitus in the United States. JAMA. 2003;290:1884-1890.

6. Giammattei J, Blix G, Marshak H, et al. Television watching and soft drink consumption: associations with obesity in 11- to 13-year-old schoolchildren. Arch Pediatr Adolesc Med. 2003;157:882-886.

7. Powell LM, Nguyen BT, Han E. Energy intake from restaurants: demographics and socioeconomics, 2003-2008. Am J Prev Med. 2012;43:498-504.

8. Bowman SA, Gortmaker SL, Ebbeling CB, et al. Effects of fast-food consumption on energy intake and diet quality among children in a national household survey. Pediatrics. 2003;113:112-118.

9. Kessler M. Getting Hispanics in the QSR Door. New York, NY: Univision Communications, Inc., 2012.

10. Kann L, Kinchen S, Shanklin SL, et al. Youth risk behavior surveillanceUnited States, 2013. MMWR. Suppl 2014;63:1-168.

11. Campbell JM. Muy local: Differentiating Hispanic and Caucasian shoppers of locally produced foods in US grocery. J Retailing Consumer Servic. 2013;20:325-333.
12. The Shelbey Report. Hispanic Buying Power. 2011. Available at www.theshelbyreport.com/2011/07/01/hispanic-buying-power Accessed May 13, 2016.

13. Harris JL, Schwartz MB, Munsell CR, et al. Fast food FACTS 2013: Measuring progress in nutrition and marketing to children and teens. 2013. Available at www.fastfoodmarketing.org/media/ FastFoodFACTS_report.pdf Accessed May 13, 2016.

14. Advertising Age 11th Annual Hispanic Fact Pack. Detroit, Ml: Crain Communication, Inc., 2014.

15. Center for Digital Democracy. Targeting the "Digital Latino". 2013. https:// www.democraticmedia.org/sites/default/files/ Targeting\%20Digital\%20LatinosMAy2013.pdf Accessed May 13, 2016.

16. Fleming-Milici F, Harris JL, Sarda V, et al. Amount of Hispanic youth exposure to food and beverage advertising on Spanish- and Englishlanguage television. JAMA Pediatr. 2013;167:723-730.

17. Adeigbe RT, Baldwin S, Gallion K, et al. Food and beverage marketing to Latinos: A systematic literature review. Health Educ Behav. 2015;42: 569-582.

18. Federal Trade Commission. A Review of Food Marketing to Children and Adolescents: follow-Up Report. 2012. Available at https://www.ftc.gov/ sites/default/files/documents/reports/review-food-marketing-childrenand-adolescents-follow-report/121221foodmarketingreport.pdf Accessed December 10, 2014.

19. Lingas EO, Dorfman L, Bukofzer E. Nutrition content of food and beverage products on web sites popular with children. Am J Public Health. 2009;99(Suppl 3):S587-S592.

20. Harris JL, Schwartz MB, LoDolce M, et al. Sugary drink FACTS 2014: Some progress but much room for improvement in marketing to youth. 2014. Available at www.sugarydrinkfacts.org/resources/ sugarydrinkfacts_report.pdf Accessed May 13, 2016.

21. Harris JL, Schwartz MB, Shehan, C, et al. Snack FACTS 2015: Evaluating snack food nutrition and marketing to youth. 2015. Available at www.uconnruddcenter.org/files/Pdfs/SnackFACTS_2015_Fulldraft03.pdf Accessed June 5, 2017.

22. comScore Media Metrix Key Measures. July 2012-June 2013. Available at www.comscore.com Accessed December 6, 2014.

23. Gordon-Larsen P, Harris KM, Ward DS, et al. Acculturation and overweightrelated behaviors among Hispanic immigrants to the US: the National Longitudinal Study of Adolescent Health. Soc Sci Med. 2003;57:2023-2034.

Cite this article as: Hyary M, Harris $J L$ (2017) Hispanic youth visits to food and beverage company websites, Health Equity 1:1, 134-138, DOI: $10.1089 /$ heq.2016.0026.

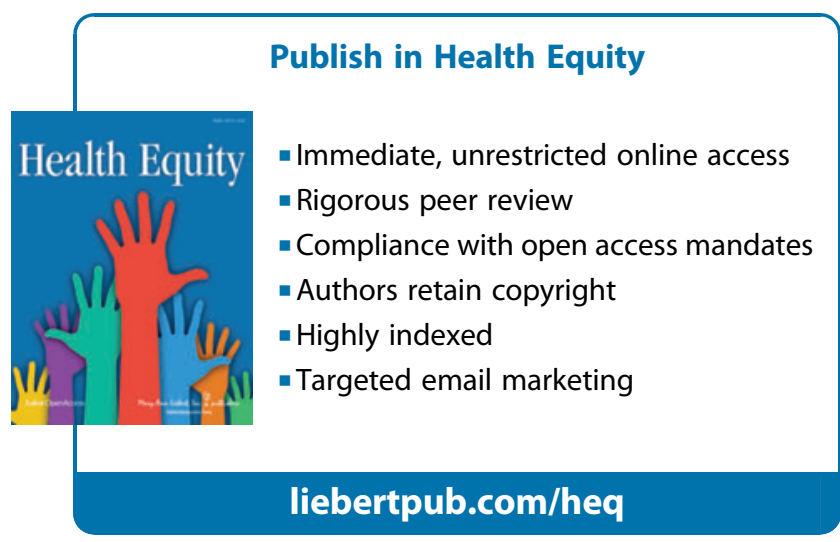

